\title{
COMPORTAMENTO DE CULTIVARES DE TOMATE CEREJA EM SUBSTRATOS ALTERNATIVOS
}

Maria Jose Marques ${ }^{1}$; Adrian Arturo Arispe Torrez²; Ariel Dotto Blind ${ }^{3}$; Jose Nilton Rodrigues Figueiredo ${ }^{4}$; Danilo Fernandes Silva Filho ${ }^{5}$

${ }^{1}$ Engenheira Agrônoma, Mestra em Agricultura, Instituto Nacional de Pesquisas da Amazônia (INPA), Manaus-AM, Brasil.

${ }^{2}$ Engenheiro Florestal, Mestre em Biotecnologia e Recursos Naturais, Universidade do Estado do Amazonas (UEA), Manaus-AM, Brasil.

${ }^{3}$ Engenheiro Agrônomo, D.Sc em Agronomia, Técnico da Estação Experimental de Hortaliças, Instituto Nacional de Pesquisas da Amazônia (INPA), (Manaus-AM, Brasil. (ariel.blind@inpa.gov.br)

${ }^{4}$ Engenheiro Agrônomo, Mestre em Agricultura, Técnico da Estação Experimental de Hortaliças, Instituto Nacional de Pesquisas da Amazônia (INPA), (Manaus-AM, Brasil.

${ }^{5}$ Engenheiro Florestal, D.Sc em Genética, Pesquisador do Instituto Nacional de Pesquisas da Amazônia (INPA), (Manaus-AM, Brasil.

Recebido em: 06/04/2018 - Aprovado em: 10/06/2018 - Publicado em: 20/06/2018 DOI: 10.18677/EnciBio_2018A29

\begin{abstract}
RESUMO
$\mathrm{Na}$ Amazônia central, diversas hortaliças são exploradas comercialmente por agricultores com a mesma qualidade de produtos já consolidados no mercado. A produção de mudas de cultivares adaptadas, com formulações alternativas de substratos podem contribuir para diminuir os custos de produção e trazer vantagens agroambientais aos produtores regionais. Neste sentido o presente trabalho teve por objetivo, avaliar o desempenho de mudas de cultivares regionais de tomate cereja em substratos alternativos. Foram utilizados quatro cultivares regionais de tomate cereja: Nishoy, Yoshin, Shony e a cultivar comercial Carolina em quatro formulações de substrato: Latossolo + Esterco de frango 8:1, Latossolo + NPK 20-20-20 100:1; Composto orgânico e substrato comercial Plantmax ${ }^{\circledR}$. O experimento foi conduzido em casa de vegetação, delineamento inteiramente ao acaso, esquema fatorial $4 \times 4$ (cultivares $x$ substratos), com quatro repetições. Aos 25 dias após a semeadura nas bandejas de 128 células, foram avaliadas nas mudas a altura, diâmetro do colo e número de folhas. Não houve interação entre os fatores cultivares $x$ substratos. As cultivares Shony e Carolina apresentaram desempenhos superiores para todos os caracteres avaliados. Os substratos: Latossolo + NPK 20-20-20 100:1; Composto orgânico e Plantmax ${ }^{\circledR}$ apresentam funções semelhantes para altura e número de folhas entre as cultivares avaliadas. A combinação de substratos Latossolo + NPK e Composto orgânico, aliado a cultivar de tomate Shony, apresentaram resultados promissores à utilização de produtos de baixo custo e com qualidade semelhante aos comerciais.
\end{abstract}

PALAVRAS-CHAVE: Lycopersicon esculentum, Mudas, Nishoy, Shony, Yoshin. 


\title{
BEHAVIOR OF CHERRY TOMATO CULTIVARS IN ALTERNATIVE SUBSTRATES
}

\begin{abstract}
In the central Amazon, several vegetables are commercially exploited by farmers with the same quality of products already consolidated in the market. The production of seedlings of adapted cultivars with alternative formulations of substrates can contribute to lower production costs and bring agri-environmental advantages to regional producers. In this sense, the objective of this work was to evaluate the performance of seedlings of regional cultivars of cherry tomatoes on alternative substrates. Four regional cultivars of cherry tomato were used: Nishoy, Yoshin, Shony and Carolina commercial cultivar $\mathrm{x}$ four substrate formulations: Latosol + Chicken Spittle 8:1, Latosol + NPK 20-20-20 100:1; Organic compound and commercial substrate Plantmax ${ }^{\circledR}$. The experiment was conducted in a greenhouse completely randomized design, in a $4 \times 4$ factorial scheme (cultivars $x$ substrates), with four replicates. Twenty-five days after sowing in the 128-cell trays were evaluated in the seedlings: height, diameter of the lap and number of leaves. There was no interaction between the cultivars $x$ substrates. The cultivars Shony and Carolina presented superior performances for all evaluated characters. The substrates: Latosol + NPK 20-20-20 100:1; Organic compound and Plantmax ® present similar functions for height and number of leaves among the cultivars evaluated. The combination of substrates Latosol + NPK and Organic Compound, together with Shony tomato cultivar, presented promising results for the use of low cost and commercial quality products.
\end{abstract}

KEYWORDS: Lycopersicon esculentum, Seedlings, Nishoy, Shony, Yoshin.

\section{INTRODUÇÃO}

O tomate cereja (Lycopersicon esculentum Mill) é amplamente utilizado na culinária do Brasil em diversas iguarias, principalmente no preparo de molhos e caldos, o quê eleva a demanda desta hortaliça em qualquer classe social (GUSMÃO et al., 2006; ARAUJO et al., 2017). Outro fator que torna o cultivo de tomate cereja atrativo é a rentabilidade na produção. Negrisoli et al. (2015) avaliando a viabilidade econômica do tomate cereja Sweet grape demostraram uma lucratividade de até 80 $\%$ sobre as receitas investidas, exceto custos de infraestrutura. Desta forma, o incentivo à produção deste tipo de hortaliça é oportuno ainda mais onde o consumo é acentuado. Na região norte do Brasil, as condições edafoclimaticas desfavorecem a produção de olericolas que não sejam adaptadas as condições locais, o que torna a produção de hortaliças super lucrativa, porem com este desafio a parte (PENA et al., 2010).

A produção de mudas sadias e de boa qualidade torna-se uma das etapas mais importantes na produção de hortaliças (RODRIGUES et al., 2010; ARAUJO et al., 2017) isto porque tão importante quanto considerar o profissionalismo previsto durante o cultivo é começar com um estande de mudas de alta qualidade. Mudas de cultivares adaptadas proporcionam normalmente estandes uniformes e com melhor tolerância a estresse bióticos e abióticos (FERREIRA et al., 2013). A maioria das cultivares comerciais de tomate cereja que estão disponíveis no mercado apresentam pouca ou nenhuma tolerância ao calor ou quando tolerantes, não apresentam bom desenvolvimento em regiões úmidas, como é o caso da Amazônia (MARTINS et al., 2013), além disso, ainda existe o complexo de murcha bacteriana que pode provocar perda total das plantas, quando estas não são tolerantes e/ou resistentes (COELHO NETO et al., 2003). Diante disso a utilização de cultivares 
desenvolvidas na região onde se pretende produzir em larga escala torna-se indispensável, sendo muito relevante para o sucesso da atividade olericola.

Outro fator a ser considerado é a disponibilidade de substratos de qualidade e que sejam economicamente viáveis a formação de uma muda vigorosa em tempo hábil, de 20 a 30 dias, dependendo da interação genótipo x ambiente (FILGUEIRA, 2008; NADAl et al., 2015). De acordo com Menezes et al. (2000) desenvolver sua própria formulação de substrato para uma adequada formação de mudas pode ser muito vantajoso ao agricultor, no entanto, é necessário considerar além da qualidade, custo $x$ benefício de insumos que o compõem (COSTA et al., 2013). Desta forma, ampliar opções que possam amortizar os custos de produção e manter a qualidade do produto, pode refletir em maiores lucros ao agricultor e destinar corretamente matérias primas da região.

Posto isto, o objetivo deste trabalho foi avaliar o desenvolvimento de mudas de cultivares de tomate cereja selecionadas e adaptadas ao clima amazônico, comparando-se com uma cultivar comercial e verificar o comportamento destas mudas em diferentes composições de substratos de fácil aquisição ao agricultor da região.

\section{MATERIAL E MÉTODOS}

O experimento foi desenvolvido em casa de vegetação tipo capela na Estação Experimental de Hortaliças "Dr. Alejo von der Pahlen" nas coordenadas de latitude 2 59'S, longitude 60 01'W e altitude de 60 m, do Instituto Nacional de Pesquisa da Amazônia, (INPA) no mês de outubro de 2016. O clima local é tipo "equatorial quente e úmido" na classificação de Köppen-Geiger com temperatura média de 27,4 ${ }^{\circ} \mathrm{C}$ e precipitação média de aproximadamente $2300 \mathrm{~mm}$.ano-1.

As cultivares de tomate cereja utilizadas; Nishoy, Yoshin e Shony desenvolvidas pelo Instituto Nacional de Pesquisas da Amazônia (INPA) entre os anos de 2013 a 2016, apresentam resistência horizontal ao complexo Ralstonia solanacearum e a cultivar comercial Carolina ${ }^{\circledR}$. Os seguintes substratos foram propostos: I) Latossolo + Esterco de frango na proporção 8:1, II) Latossolo + NPK 20-20-20 100:1, III) Composto orgânico (liteira, serragem, esterco de frango, na proporção 7:7:1), e substrato comercial Plantmax ${ }^{\circledR}$.

Os substratos I e III receberam homogeneização de forma manual 30 dias antes da instalação do experimento, reservado em local arejado e protegido da chuva. O latossolo utilizado no substrato I e II adveio a $30 \mathrm{~cm}$ de profundidade na própria área da estação experimental e esteve associado a fertilização NPK e/ou combinado com esterco de frango. Todos os substratos foram colocados, preenchendo bandejas de isopor de 128 células.

Em cada célula da bandeja foram semeadas duas sementes a um centímetro de profundidade e após a emergência destas realizou-se o desbaste, permitindo o desenvolvimento de apenas uma plântula por célula. As bandejas estiveram dispostas em bancadas em casa de vegetação, irrigadas por microaspersão, acionadas duas vezes ao dia por 15 minutos, conforme sugestões de (FILGUEIRA, 2008; AMBROSANO et al., 2015).

As mudas receberam avaliação 25 dias após semeadura, avaliando-se os seguintes componentes; altura da muda $(\mathrm{cm})$, diâmetro do colo $(\mathrm{cm})$ e número de folhas. Para aferir a altura da muda foi utilizada régua milimétrica considerando base-solo até a região meristemática da plântula e para diâmetro do colo foi utilizado paquímetro digital, considerando a base-solo da muda. A contagem de folhas, 
abordada considerando apenas as folhas definitivas, desconsiderando as cotiledonares.

O delineamento experimental utilizando foi em blocos inteiramente casualizados, em esquema fatorial $4 \times 4$ (cultivares de tomate cereja $\mathrm{x}$ substratos), com quatro repetições e duas plantas por parcela. Os dados obtidos foram submetidos ao teste $\mathrm{F}$ e as médias comparadas pelo teste de Tukey ao nível de $5 \%$ de probabilidade $(P<0,05)$, utilizando auxilio do software estatístico Assistat $7.7 \AA$ (SILVA; AZEVEDO, 2016).

\section{RESULTADOS E DISCUSSÃO}

Pela análise de variância (ANAVA), não houve interação significativa para os componentes analisados (Tabela 1). E possível verificar que houve diferença estatística para as cultivares em todos os componentes avaliados, e para substratos, foi observada diferença estatística para altura e número de folhas respectivamente.

TABELA 1. Análise de variância das cultivares, substratos e suas interações em relação aos componentes avaliados, altura, diâmetro do colo e número de folhas, INPA, Manaus-AM. 2016.

\begin{tabular}{cccc}
\hline \multicolumn{4}{c}{ ANAVA } \\
\hline & Altura $(\mathrm{cm})$ & Diâmetro do colo $(\mathrm{cm})$ & Número de folhas \\
\hline Cultivares (C) & $91,8458^{* *}$ & $26,6875^{* *}$ & $73,5330^{* *}$ \\
Substratos (S) & $11,3965^{* *}$ & $2,3487 \mathrm{~ns}$ & $6,9120^{* *}$ \\
Interação C x S & $1,1569 \mathrm{~ns}$ & $1,7363 \mathrm{~ns}$ & $0,6919 \mathrm{~ns}$ \\
\hline
\end{tabular}

*Significativo ao nível de $5 e^{* *} 1 \%$ respectivamente.

${ }^{\text {ns }}$ Não significativo pelo teste $\mathrm{F}$

Os resultados obtidos confirmam que entre as cultivares e entre substratos é possível ajuizar e combinar opções que se traduzem em melhor custo benefício. Evidentemente a cultivar Carolina seguido da cultivar Shony apresentaram os maiores resultados para o porte, acumulando altura de $13,98 \mathrm{~cm}_{\text {planta-1 }}$ e $^{11,30 \mathrm{~cm}}$ planta $^{-1}$, respectivamente (Tabela 2). A altura acumulada de uma muda reflete sua capacidade e responsividade sobre o fator de cultivo, sendo factível admitir que um porte superior em uma muda, possa se traduzir em maior número de folhas e como consequência isso leva a compreensão que existe melhor interação com aporte físico x químico do substrato, como observado neste ensaio (Tabela 2).

TABELA 2. Resultado da altura de mudas em cultivares de tomate cereja em diferentes substratos, INPA, Manaus-AM, 2016.

\begin{tabular}{cccccc}
\hline & \multicolumn{4}{c}{${\text { Característica avaliada }{ }^{1}}$} & \\
\cline { 2 - 5 } Tratamentos & Sub I & Sub II & Sub III & Plantmax ${ }^{\circledR}$ & Médias \\
\cline { 2 - 5 } & 10,6 & 14,35 & 14,95 & 16,02 & $13,98 \mathrm{a}$ \\
Carolina & 4,35 & 4,95 & 5,65 & 6,15 & $5,27 \mathrm{c}$ \\
Nishoy & 3,50 & 6,45 & 6,77 & 6,85 & $5,80 \mathrm{c}$ \\
Yoshin & 9,33 & 12,71 & 12,30 & 10,87 & $11,30 \mathrm{~b}$ \\
Shony & $6,85 \mathrm{~B}$ & $9,61 \mathrm{~A}$ & $9,91 \mathrm{~A}$ & $9,97 \mathrm{~A}$ & \\
\hline Médias & \multicolumn{5}{c}{19,51} \\
\hline CV \% & \multicolumn{5}{c}{ Altura (cm) } \\
\hline
\end{tabular}

${ }^{1}$ médias seguidas de mesma letra nas linhas e nas colunas não diferem entre si pelo teste de tukey ao nível de $5 \%$ de significância 
Nadai et al. (2015), relatam que na produção de mudas de tomate em diferentes substratos o que deve anteceder prioritariamente a sua produção em si é idealizar a qualidade, haja visto que pouco adiantaria investir em um plantio comercial, sendo que a muda vigorosa, sadia e de qualidade é o insumo de maior relevância, todavia o custo $x$ benefício deve ser considerado em cada região.

O diâmetro de colo reflete em parte o estádio de vigorosidade e tem relação bem mais especifica do que a sustentação vegetal, sobre tudo a eficiência na translocação de foto assimilados raiz-parte aérea. Observa-se na Tabela 3 que a cultivar Shony e Carolina não diferiram entre si para este atributo, com 0,24 e 0,25 $\mathrm{cm}$ planta $^{-1}$, respectivamente. As Cultivares Yoshin e Nishoy apresentaram colo relativamente diminuto, porém não é possível predizer se esta característica possui especificidade com ambiente ou é característica genotípica. Todavia é importante admitir a escolha de cultivares que apresentem colo mais espesso, o que poderá implicar no vigor geral da planta e sua capacidade produtiva (COSTA et al., 2013).

TABELA 3. Resultado do diâmetro de colo de mudas em cultivares de tomate cereja em diferentes substratos. INPA, Manaus-AM, 2016.

\begin{tabular}{cccccc}
\hline & \multicolumn{4}{c}{ Característica avaliada ${ }^{1}$} & \\
\cline { 2 - 5 } Tratamentos & Sub I & Sub II & Sub III & Plantmax ${ }^{\circledR}$ & Médias \\
\cline { 2 - 5 } & 0,16 & 0,3 & 0,25 & 0,31 & $0,25 \mathrm{a}$ \\
Carolina & 0,11 & 0,12 & 0,1 & 0,13 & $0,12 \mathrm{~b}$ \\
Nishoy & 0,11 & 0,15 & 0,12 & 0,14 & $0,13 \mathrm{~b}$ \\
Yoshin & 0,25 & 0,24 & 0,25 & 0,21 & $0,24 \mathrm{a}$ \\
Shony & $0,16 \mathrm{~A}$ & $0,20 \mathrm{~A}$ & $0,18 \mathrm{~A}$ & $0,20 \mathrm{~A}$ & \\
\hline Médias & \multicolumn{5}{c}{29,57} \\
\hline CV \% & \multicolumn{5}{c}{}
\end{tabular}

Entre os substratos, todos proporcionaram efeito satisfatório de diâmetros de colo semelhante aos resultados encontrados por Nadai et al. (2015) e Costa et al. (2013), sendo o substrato II e o Plantmax os materiais que apontaram os maiores valores. É importante observar que o custo de produção por kg de substrato pode ser o diferencial para determinar a escolha e consequentemente diminuir os custos sem que ocorra perda de qualidade da muda.

Com relação ao número de folhas que as cultivares proporcionaram sob os diferentes substratos, pode-se observar que entre as cultivares, Shony e Carolina acumularam maior número de folhas expandidas com 5,09 e 5,18 folhas planta-1 (Tabela 4). Costa et al. (2013) e Araujo et al. (2017) asseguram que quanto maior for o acúmulo de folhas sob um determinado período que um substrato proporcionar, melhor será o pós transplante e vida útil desta muda, porem deve ser considerado a própria capacidade genotípica da cultivar e/ ou variedade de tomate que se pretende explorar. 
TABELA 4. Resultado do número de folhas em plantas de cultivares de tomate cereja em diferentes substratos. INPA, Manaus-AM, 2016.

\begin{tabular}{cccccc}
\hline & \multicolumn{4}{c}{ Característica avaliada ${ }^{1}$} & \\
\cline { 2 - 5 } Tratamentos & Sub I & Sub II & Sub III & Plantmax ${ }^{\circledR}$ & Médias \\
\cline { 2 - 5 } & 4,62 & 5,75 & 4,75 & 5,62 & $5,18 \mathrm{a}$ \\
\hline Carolina & 2 & 2,62 & 2 & 2,62 & $2,31 \mathrm{~b}$ \\
Nishoy & 1,5 & 3,37 & 2,5 & 2,87 & $2,56 \mathrm{~b}$ \\
Yoshin & 5 & 5,5 & 4,75 & 5,12 & $5,09 \mathrm{a}$ \\
Shony & $3,28 \mathrm{C}$ & $4,31 \mathrm{~A}$ & $3,50 \mathrm{BC}$ & $4,06 \mathrm{AB}$ \\
\hline Médias & \multicolumn{5}{c}{19,26} \\
\hline CV \% & \multicolumn{5}{c}{} \\
\hline${ }^{1}$ médias seguidas de mesma letra nas linhas e nas colunas não diferem entre si pelo teste de tukey ao nível de 5 \\
\% de significância
\end{tabular}

O substrato que proporcionou maior número de folhas foi a mistura de 100:1 de latossolo + NPK 20-20-20. Isto se deve em parte, pelo fato de que fisicamente o latossolo é bem estruturado, conforme apontam Pena et al. (2010), porém quimicamente é muito pobre, além do que não possui quantidades significativas de material orgânico. Isto leva a compreensão sobre a incorporação de elementos e sua disponibilidade prontamente equilibrada, contribuindo assim para formação desejada de uma muda, conforme observado neste ensaio.

Segundo resultados de Costa et al. (2013) para que um composto seja adequado como substrato é necessário que haja mistura com diversos materiais, nas proporções corretas. O esterco de frango é rico em nitrogênio, porem grande parte é gasto e imobilizado por bactérias durante diversas reações da decomposição (LEAL et al., 2007). O N é constituinte de macromoléculas, sobre tudo ativador celular, responsável por sinalizar o crescimento vegetal, principalmente a parte aérea, contudo, pode estar limitante com outros elementos, consequentemente menor será o número de folhas na planta o que pode interferir no desempenho vegetativo.

Foi possível analisar que o substrato que continha apenas latossolo + esterco de frango proporcionou os menores resultados devido à presença mais evidente do $\mathrm{N}$. Isto pode ser verificado observando-se o substrato composto, que além da liteira, continha serragem de madeira, contribuindo com maior relação C:N (AMBROSANO et al., 2015; ARAUJO et al., 2017). Desta forma, na parte do $\mathrm{N}$ do esterco pode ter sido utilizado para a decomposição deste material, proporcionando outros elementos que atuam em conjunto no metabolismo vegetal.

De maneira geral quando o esterco de frango é utilizado com outros insumos em proporções adequadas, pode ser uma excelente alternativa ao agricultor (LEAL et al., 2007; NEGRISOLI et al., 2015) considerando que a exigência de $\mathrm{N}$ não deve ser alta uma vez que está na forma orgânica (ARAUJO et al., 2017). Trabalhos de Ferreira et al. (2013) e Costa et al. (2013) utilizando o substrato comercial constataram bons resultados para componentes de qualidade de muda, evidenciando a eficácia, todavia o agricultor pode optar por substratos caseiros de fácil aquisição e custo reduzido. 


\section{CONCLUSÕES}

Os substratos propostos latossolo + NPK 20-20-20 e composto orgânico demostraram eficiência semelhante ao composto comercial Plantmax para a altura, diâmetro do colo e número de folhas em plântulas de cultivares de tomate cereja;

A cultivar de tomate cereja Shony, mostrou-se superioridade no desenvolvimento em fase de muda comparando-se com Yoshin e Nishoy, apresentando-se estatisticamente igual a cultivar comercial Carolina.

\section{REFERÊNCIAS}

AMBROSANO, E.; ROSSI, F.; DIAS, F.; TAVARES, S.; AMBROSANO, G. Desempenho do Tomate-Cereja e Milho-Verde Após Cultivo de Fabaceas e Seu Efeito no Solo. Cadernos De Agroecologia, v.9 n.4. 2015. Disponível em: http://revistas.aba-agroecologia.org.br/index.php/cad/article/view/16773

ARAUJO, T. da S.; ALMEIDA, A.S.; ARAÚJO, F.S.; FERREIRA, A.H.C.; PASCOA PINTO, T. da. Produção e qualidade de tomates cereja fertirrigados com água residuária da piscicultura. Revista Verde de Agroecologia e Desenvolvimento Sustentável. V.12, $\mathrm{n} \quad 3, \quad$ p. 392-396, 2017. Disponível em: http://www.gvaa.com.br/revista/index.php/RVADS. Doi: http://dx.doi.org/10.18378/rvads.v12i3.4775.

COELHO NETO, R.A.; PEREIRA, B.G.; NODA, H.; BOHER, B. Caracterização de isolados de Ralstonia solanacearum obtidos de tomateiros em várzea e em terra firme, no Estado do Amazonas. Fitopatologia Brasileira, v.28, n,4, p,362-366, 2003. Disponível em:< http://dx.doi.org/10.1590/S0100-41582003000400003 >. Doi: 10.1590/S0100-41582003000400003.

COSTA, L.A.M.; COSTA, M.S.S.; PEREIRA, D.C.; BERNARDI, F.H.; MACCARI, S. Avaliação de substratos para a produção de mudas de tomate e pepino. Revistas Ceres, v.60 n. 5, p.676-682, 2013. Disponível em: < http://dx.doi.org/10.1590/S0034737X2013000500011 >. Doi: 10.1590/S0034-737X2013000500011.

FERREIRA, R.L.; FORTI, V.A.; SILVA, V.N.; MELLO, S.C. Temperatura inicial de germinação no desempenho de plântulas e mudas de tomate. Ciência Rural, v.43, n.7, p.1189-1195, 2013. Disponível em :< http://dx.doi.org/10.1590/S010384782013000700008 >. Doi: 10.1590/S0103-84782013000700008.

FILGUEIRA FAR. Novo manual de olericultura: agrotecnologia moderna na produção e comercialização de hortaliças. Viçosa: 3ed. Ed. UFV, 2008. 421p.

GUSMÃO, M.T.A.; GUSMÃO, S.A.L; ARAÚJO, J.A.C. Produtividade de tomate tipo cereja cultivado em ambiente protegido e em diferentes substratos. Horticultura Brasileira, v.24, n.4, p.431-436, 2006. Disponivem em:< http://dx.doi.org/10.1590/S0102-05362006000400007>. Doi: 10.1590/S010205362006000400007.

LEAL, M.A.A.; GUERRA, J.G.M.; PEIXOTO, R.T.G.; ALMEIDA, D.L. Utilização de compostos orgânicos como substratos na produção de mudas de hortaliças.

Horticultura Brasileira, v. 25, n. 3, p. 392-395, 2007. Disponível em: < http://www.alice.cnptia.embrapa.br/alice/handle/doc/629551 >. 
MARTINS, L.H.P.; NODA, H; MENDONÇA, M.S.P.; MACHADO, F.M. Tomate Yoshimatsu - uma cultivar adaptada ao trópico úmido brasileiro. In: Noda, $\mathrm{H}$.; Silva Filho, D.F.; Souza, L.A.G. Agricultura familiar no Amazonas: conservação dos recursos ambientais. $1^{\mathrm{a} e d}$. Manaus: NERUA/Instituto Nacional de Pesquisas da Amazônia, 2013. P.15-26. Disponível em: https://www.inpa.gov.br/arquivos/Agricultura_Familiar_Vol_1.pdf

NADAI, F.B.; MENEZES, J.B.C.; CATÃO, H.C.R.M.; ADIVÍNCULA, T.; COSTA, C.A. Produção de mudas de tomateiro em função de diferentes formas de propagação e substratos. Revista agro@mbiente On-line, v.9, n.3, p,261-267, 2015. Disponível em:< http://dx.doi.org/10.18227/1982-8470ragro.v9i3.2348 >. Doi: 10.18227/19828470ragro.v9i3.2348.

NEGRISOLI, R.M.; CECHINATTO, F.H.; BISSOLO, M.J.; ROSESTOLATO, L.L.R.; SABBAG, O.J. Viabilidade econômica de cultivo de minitomare sweet grape no município de Casa Branca/SP. Enciclopédia Biosfera, v.11, n.21, p.1932-1942, 2015. em:

http://www.conhecer.org.br/enciclop/2015b/agrarias/viabilidade\%20economica $\% 20$ no\%20cultivo\%20de\%20minitomate.pdf >.

PENA, M.A.A.; NODA, H.; MACHADO, F.M.; PAIVA, M.S.S. Adaptabilidade e estabilidade de genótipos de tomateiro sob cultivo em solos de terra firme e várzea da Amazônia infestados por Ralstonia solanacearum. Bragantia, v.69, n.1, p.27-37, 2010. Disponível em:< http://dx.doi.org/10.1590/S0006-87052010000100005 >. DOl: 10.1590/S0006-87052010000100005.

RODRIGUES, D.S.; LEONARDO, A.F.G.; NOMURA, E.S.; TACHIBANA, L.; GARCIA, V.A.; CORREA, C.F. Produção de mudas de tomateiro em sistemas flutuantes com adubos químicos e água residuária de viveiros de psicultura. Revista Brasileira de Ciências Agrárias, v.5, n.1, p.32-35, 2010. Disponível em :< http://www.redalyc.org/html/1190/119012589005 >.

SILVA, F, de A. S. e,; AZEVEDO, C. A. V. de. The Assistat Software Version 7,7 and its use in the analysis of experimental data. African Journal of Agricultural Research, v.11, n.39, p.3733-3740, 2016. Disponível em: < http://dx.doi.org/10.5897/AJAR2016-11522 >. Doi: 10,5897/AJAR2016,11522. 